\title{
Performance Measurement of the Fourth Party Logistics Providers
}

\section{Yu-Wei Chang}

Department of Air Transportation Management, Aletheia University, Tainan 721.

Email: uwchang@mt.au.edu.tw

Received April, 2013

\begin{abstract}
This paper presents a multicriterica decision making method (MCDM) to evaluate the performance of the fourth-party logistics providers. The four indexes of balanced scorecard (BSC) are used as the evaluation indexes. AHP (ana-lytical hierarchy process) is used for rating the weights of criteria and alternatives. MCDM method of SAW (Simple Additive Weighting) is used for ranking the companies. Results show that the approach is applicable for the performance measurement problem.
\end{abstract}

Keywords: MCDM; AHP; SAW

\section{Introduction}

To cost down and increase core competence, many companies deal with their logistics activities by the thirdparty logistics provider (3 PL). With the development of electronic commercial, a new logistics provider which is called the fourth party logistics (4 PL) is more and more popular in Taiwan. The concept of the 4PL is that it integrates the resources, capabilities, and technology of its own organization and other organizations to design, build, and run comprehensive supply chain solutions. The main difference between the 3 PL and 4 PL lies in that firms own their own assets in the 3 PL, and they perform more than one or more logistics services. However, firms do not own any type of assets in the $4 \mathrm{PL}$. The $4 \mathrm{PL}$ only arrange the logistics services and serve as an intermediary between the firm and the service provider. With the help of the 4 PL, the companies can manage the 3 PLs, truckers, forwarders, custom house agents, and others, essentially taking responsibility of a complete process for the customer.

Many traditional methods nowadays are used for the performance evaluation (i.e. data envelopment analysis, DEA; regression method and ration analysis). The drawback of the traditional methods focuses on the financial performance and ignores the non-financial performance. To solve the disadvantages of the above approaches, Kaplan and Norton (1992) proposed the Balanced Scored Card (BSC) concept to evaluate the performance of a company by four perspectives [1]. The four perspectives include financial, customer, internal business process and learning and growth. With the help of BSC evaluation, both financial and non-financial performance can be overall measured.

Analytic Hierarchy Process (AHP) is a multi-attribute decision making method proposed by Satty in 1971 [2]. It is a widely used method, providing a rational framework for solving a complex decision problem. The main ideal of the AHP is that it derives ratio scales by pairwise comparisons of attrubutes. It is a popular method utilized in a multicriteria decision making (MCDM) problem.

Many methods have been developed for solving the MCDM problems (i.e. Weighting Product, WP; Simple Additive Weighting, SAW; Technique for Order Preference by Similarity to Ideal Solution, TOPSIS). Each method has its own aim and advantages. For example, the concept of SAW is to obtain a weighted sum of the performance ratings of each alternative over all attributes. The concept of Weighted Product method is to obtain the performance ratings by multiplying contributions from attributes. The concept of TOPSIS is to obtain the performance rating by the concept that the alternative to be chosen should have the nearest distance from the positive ideal solution and the farthest distance from the negative ideal solution.

This paper presents a hybrid model that combines both AHP and BSC for performance measurement of the fourth-party logistics providers. In the model, the four indexes of BSC will be used as evaluation criteria. AHP is used for the weights of criteria, sub-criteria and alternatives. Rank of the fourth-party logistics providers is determined by the help of SAW. The advantage of the 
method is that both final and non-final perspectives are considered for the performance measurement problem of the fourth-party logistics provider at the same time.

\section{Methodology}

\subsection{AHP}

Analytic Hierarchy process (AHP) is originally proposed by Saaty in 1971 to deal with complex problems by decomposing a complex problem into a structured decision hierarchy. The first step of AHP is to establish hierarchial structure and decompose into different levels (i.e. the goal) and each level is further decomposed into sublevels (i.e. criteria) until the lowest levels of the hierarchy.

After the hierarchial structure of the problem is finished, the next step is to use pairwise comparison to determine the priority. The decision maker uses a nine point scale to assess the priority score. The procedure focuses on two factors at a time and their relation to each other with the scores $1,3,5,7$, and 9 . The score 1 refers to equal importance, 3 refers to slight more importance, 5 refers to strong more importance, 7 refers to very strong importance and 9 denotes extremely more importance. The scores of 2, 4, 6, and 8 are intermediate scores between the two judgments. If there are $\mathrm{n}$ attributes and $\mathrm{m}$ alternatives, the matrix judgment will lead to an $\mathrm{n} \times \mathrm{m}$ matrix and there are $n * m(m-1) / 2$ pairwise comparisons to be performed. The pairwise comparison maxtrix has the following form:

$$
A=\left[\begin{array}{lll}
\frac{w_{1}}{w_{1}} & \frac{w_{1}}{w_{2}} \ldots & \frac{w_{1}}{w_{n}} \\
\frac{w_{2}}{w_{1}} & \frac{w_{2}}{w_{2}} \ldots & \frac{w_{2}}{w_{n}} \\
\frac{w_{n}}{w_{1}} & \frac{w_{n}}{w_{2}} \ldots & \frac{w_{n}}{w_{n}}
\end{array}\right]
$$

where $\frac{w_{1}}{w_{2}}$ is the relative importance of the 1-th criterion over the 2-th attribute. After the pairwise comparison matrix is obtained, the weights need to be calculated. Satty (1977) ustilizes the maximal eigenvalue method to find the value vector of $\mathrm{w}$. The exact values of $\mathrm{w}_{1}, \mathrm{w}_{2}, \ldots$, $\mathrm{W}_{\mathrm{n}}$ are computed and finally normalized as follows:

$$
\mathrm{w}_{1}+\mathrm{w}_{2}+\ldots+\mathrm{w}_{\mathrm{n}}=1
$$

The consistency property of the matrix needs to be checked to ensure the consistency of judgments in the pairwise comparison. Both the consistency index (C.I.) and consistency ratio (C.R.) are defined as follows:

$$
\text { C.I }=\frac{1}{n-1}\left(\lambda_{\max }-n\right)
$$

$\lambda_{\max }$ : The maximal eigenvalue

$n$ : The number of items being compared in the matrix

The closer the C.I. value is to 0 , the greater the consistency and acceptable. The C.I. value less than 0.1 is generally acceptable. After checking the consistency index, the consistency ratio is then examined.

$$
\text { C.R. }=\frac{\text { C.I. }}{\text { R.I. }}
$$

R.I. $=$ The average consistency index.

when C.R. $\leq 0.1$, the weights obtained by the eigen- value method are acceptable.

\subsection{The Simple Additive Weighting (SAW)}

The SAW method is one of the most widely used MADM method [3]. The basic concept of the SAW is to obtain a weighted sum of the performance ratings of each alternative over all attributes. One need to scale the scores, apply weights and sum up the values for each alternative. The SAW method requires normalizing the decision matrix (y) to allow a comparable scale for all ratings in $X$ by

$$
\begin{aligned}
& r_{i j}=\left\{\begin{array}{l}
\frac{y_{i j}}{\max _{i} y_{i j}}, \text { if } j \text { is a benefit attribute } \\
\frac{\min _{i} y_{i j}}{y_{i j}}, \text { if } j \text { is a cost attribute }
\end{array}\right. \\
& i=1,2, \ldots, m ; j=1,2, \ldots, n
\end{aligned}
$$

where $r_{i j}\left(0 \leq r_{i j} \leq 1\right)$ is defined as the normalized performance rating of alternative $A_{i}$ on attribute $C_{j}$. This normalization process transforms all the ratings in a proportional way, so that the relative order of magnitude of the ratings remains equal. The overall preference value of each alternative $\left(V_{i}\right)$ is obtained by

$$
V_{i}=\sum_{j=1}^{n} w_{j} r_{i j} \quad i=1,2, \ldots, m
$$

The greater the value $\left(V_{i}\right)$, the more preferred the alternative $\left(A_{i}\right)$. Research results have shown that the linear form of trade-offs between attributes used by the SAW method produces extremely close approximations to complicated nonlinear forms, while maintaining far easier to use and understand (Hwang and Yoon 1981).

\section{Empirical Results}

To illustrate how the proposed method can be used to evaluate the performance measurement of the fourthparty logistics, an empirical case will be used to explain it. In the case, five decision makers $\left(D_{1}, D_{2}, \ldots, D_{5}\right)$ are formulated as a team to evaluate the performance of 6 logistics providers. The DMs decide to evaluate the performance of logistics providers based on BSC. The best 
choices will be assessed based on four evaluation criteria: financial $\left(\mathrm{C}_{1}\right)$, customer $\left(\mathrm{C}_{2}\right)$, internal business process $\left(\mathrm{C}_{3}\right)$ and learning and growth $\left(\mathrm{C}_{4}\right)$, eight sub-criteria: sales profit $\left(\mathrm{c}_{11}\right)$, cash flow $\left(\mathrm{C}_{12}\right)$, customer satisfaction $\left(\mathrm{C}_{21}\right)$, customer retention $\left(\mathrm{C}_{22}\right)$, customer complaint $\left(\mathrm{C}_{31}\right)$, sales profit $\left(\mathrm{C}_{32}\right)$, training and skill $\left(\mathrm{C}_{41}\right)$, innovation $\left(\mathrm{C}_{42}\right)$ and, finally the alternatives. Figure 1 illustrates the hierarchy framework for evaluation.

\subsection{Calculate the Weights of Criteria}

Firstly, the pairwise comparisons matrix of 4 criteria are determined by 5 DMs. After rating each DMs' pairwise comparisons matrix, both C.I. and C.R. are examined. Results show that both the two indexes are acceptable. By the calculating process, we can get the weight of criteria. Table 1 shows the weights of each criteria $\left(C_{1}-C_{4}\right)$ of 5 DMs $\left(D_{1}-D_{5}\right)$.

After the consistency test, the weights of attribute are calculated, individual's judgment is integrated into group judgment by geometric mean method, and the weights of

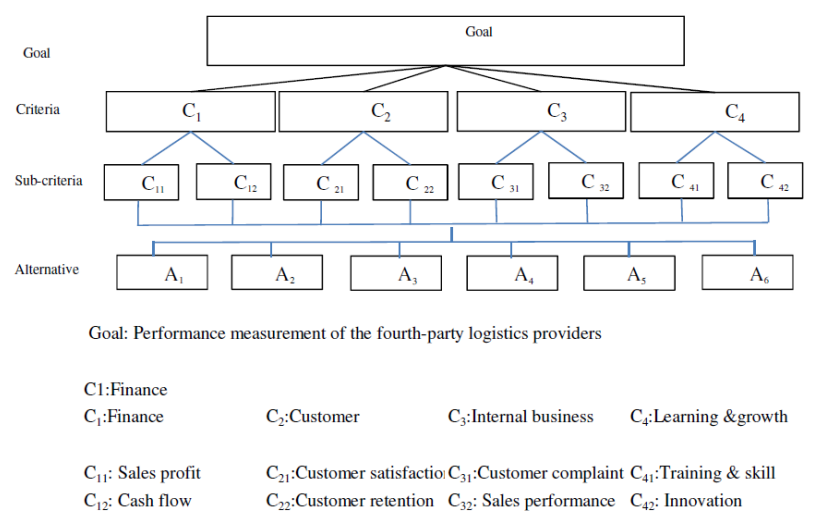

Figure 1. The Hierarchy for performance evaluation of fourth-party logistics provides.

Table 1. Weight of criteria.

\begin{tabular}{cccccc}
\hline & $\mathrm{D}_{1}$ & $\mathrm{D}_{2}$ & $\mathrm{D}_{3}$ & $\mathrm{D}_{4}$ & $\mathrm{D}_{5}$ \\
\hline $\mathrm{C}_{1}$ & 0.322 & 0.325 & 0.227 & 0.100 & 0.080 \\
$\mathrm{C}_{2}$ & 0.169 & 0.144 & 0.231 & 0.192 & 0.448 \\
$\mathrm{C}_{3}$ & 0.269 & 0.253 & 0.376 & 0.495 & 0.125 \\
$\mathrm{C}_{4}$ & 0.239 & 0.278 & 0.167 & 0.212 & 0.347 \\
\hline
\end{tabular}

Table 2. Priority weights of criteria.

\begin{tabular}{ccc}
\hline & Weight of criteria & Rank \\
\hline $\mathrm{C}_{1}$ & 0.197 & 4 \\
$\mathrm{C}_{2}$ & 0.238 & 3 \\
$\mathrm{C}_{3}$ & 0.301 & 1 \\
$\mathrm{C}_{4}$ & 0.264 & 2 \\
Sum & 1 & \\
\hline
\end{tabular}

criteria are determined. Table 2 shows the weights of each criteria. The weights of criteria are internal business process $(0.301)$, learning and growth $(0.264)$, customer (0.238) and finance $(0.163)$.

\subsection{Calculate the Weights of Sub-Criteria}

With each DM's pair-wise comparison, and assign them relative scores, the weights of each DM's sub-criteria are determined. Each DM's judgment is then integrated into group judgment by geometric mean method, and the group DM'S weights of criteria are determined. After determining the weight of criteria and sub-criteria, the overall weights of sub-criteria are then determined by SAW. Table 3 and Table 4 show the weights and overall weights of sub-criteria.

\subsection{Calculate the Weights of Alternatives}

In the next step, the performance values of different logistics providers are then determined. Table 5 and Table 6 illustrate the weights of alternatives.

\subsection{Ranking Results}

After rating the weights of each sub-criteria and alternatives, SAW will be used to evaluate the alternatives. The

Table 3. Weights and overall weights of sub-criteria.

\begin{tabular}{|c|c|c|c|c|}
\hline \multirow{3}{*}{ Weight of criteria } & \multicolumn{3}{|c|}{$\mathrm{C}_{1}$} & \multirow[t]{2}{*}{$\mathrm{C}_{2}$} \\
\hline & \multicolumn{2}{|c|}{0.197} & 0.238 & \\
\hline & $\mathrm{C}_{11}$ & $\mathrm{C}_{12}$ & $\mathrm{C}_{21}$ & $\mathrm{C}_{22}$ \\
\hline Sub-criteria & 0.282 & 0.718 & 0.243 & 0.757 \\
\hline Overall weight & 0.056 & 0.142 & 0.058 & 0.180 \\
\hline
\end{tabular}

Table 4. Weights and overall weights of sub-criteria.

\begin{tabular}{|c|c|c|c|c|}
\hline \multirow{3}{*}{ Weight of criteria } & \multicolumn{3}{|c|}{$\mathrm{C}_{3}$} & \multirow[t]{2}{*}{$\mathrm{C}_{4}$} \\
\hline & \multicolumn{2}{|c|}{0.301} & 0.264 & \\
\hline & $\mathrm{C}_{31}$ & $\mathrm{C}_{32}$ & $\mathrm{C}_{41}$ & $\mathrm{C}_{42}$ \\
\hline Sub-criteria & 0.478 & 0.522 & 0.684 & 0.316 \\
\hline Overall weight & 0.144 & 0.157 & 0.180 & 0.083 \\
\hline
\end{tabular}

Table 5. Weights of alternatives.

\begin{tabular}{ccccc}
\hline & $\mathrm{C}_{11}$ & $\mathrm{C}_{12}$ & $\mathrm{C}_{21}$ & $\mathrm{C}_{22}$ \\
\hline $\mathrm{A}_{1}$ & 0.176 & 0.222 & 0.223 & 0.145 \\
$\mathrm{~A}_{2}$ & 0.124 & 0.161 & 0.121 & 0.186 \\
$\mathrm{~A}_{3}$ & 0.191 & 0.221 & 0.174 & 0.097 \\
$\mathrm{~A}_{4}$ & 0.256 & 0.203 & 0.276 & 0.278 \\
$\mathrm{~A}_{5}$ & 0.145 & 0.107 & 0.126 & 0.186 \\
$\mathrm{~A}_{6}$ & 0.108 & 0.086 & 0.080 & 0.108 \\
\hline
\end{tabular}


Table 6. Weights of alternatives.

\begin{tabular}{ccccc}
\hline & $\mathrm{C}_{31}$ & $\mathrm{C}_{32}$ & $\mathrm{C}_{41}$ & $\mathrm{C}_{42}$ \\
\hline $\mathrm{A}_{1}$ & 0.169 & 0.193 & 0.164 & 0.196 \\
$\mathrm{~A}_{2}$ & 0.121 & 0.208 & 0.141 & 0.224 \\
$\mathrm{~A}_{3}$ & 0.288 & 0.220 & 0.194 & 0.172 \\
$\mathrm{~A}_{4}$ & 0.259 & 0.206 & 0.264 & 0.184 \\
$\mathrm{~A}_{5}$ & 0.090 & 0.091 & 0.149 & 0.131 \\
$\mathrm{~A}_{6}$ & 0.074 & 0.081 & 0.088 & 0.093 \\
\hline
\end{tabular}

final score for each alternative is as follows,

$$
\begin{aligned}
\mathrm{A}_{1}= & 0.056 * 0.176+0.142 * 0.222+0.058 * 0.223 \\
& +0.180 * 0.145+0.144 * 0.169+0.157 * 0.193 \\
& +0.180 * 0.164+0.083 * 0.196=0.181 \\
\mathrm{~A}_{2}= & 0.056 * 0.124+0.142 * 0.161+0.058 * 0.121 \\
+ & 0.180 * 0.186+0.144 * 0.121+0.157 * 0.208 \\
& +0.180 * 0.141+0.083 * 0.224=0.073 \\
\mathrm{~A}_{3}= & 0.056 * 0.191+0.142 * 0.221+0.058 * 0.174 \\
& +0.180 * 0.097+0.144 * 0.288+0.157 * 0.220 \\
& +0.180 * 0.194+0.083 * 0.172=0.069 \\
\mathrm{~A}_{4}= & 0.056 * 0.256+0.142 * 0.203+0.058 * 0.276 \\
& +0.180 * 0.278+0.144 * 0.259+0.157 * 0.206 \\
& +0.180 * 0.264+0.083 * 0.186=0.184 \\
\mathrm{~A}_{5}= & 0.056 * 0.145+0.142 * 0.107+0.058 * 0.126 \\
& +0.180 * 0.186+0.144 * 0.090+0.157 * 0.091 \\
& +0.180 * 0.149+0.083 * 0.131=0.131
\end{aligned}
$$

$$
\begin{aligned}
A_{6}= & 0.056 * 0.108+0.142 * 0.086+0.058 * 0.080 \\
& +0.180 * 0.108+0.144 * 0.074+0.157 * 0.081 \\
& +0.180 * 0.088+0.083 * 0.093=0.093
\end{aligned}
$$

Based on the results of SAW, we can conclude that the ranking order of six companies is $A_{4}, A_{1}, A_{5}, A_{6}, A_{2}$, and $A_{3}$. In the case, the $A_{4}$ is the best one.

\section{Conclusions}

This paper proposes an effective method that combines both the AHP and SAW for the performance measurement of the fourth party logistics provider. In the evaluate context, the AHP is utilized to rate the weight of criteria, sub-criteria and alternatives. The SAW is used to rank the performance order. We can observe that the ranking of the six logistic providers is $\mathrm{A}_{4}(0.184)>$ $\mathrm{A}_{1}(0.181)>\mathrm{A}_{5}(0.131)>\mathrm{A}_{6}(0.093)>\mathrm{A}_{2}(0.073)>$ $A_{3}(0.069)$. Results show that the proposed model is comprehensible for the problem. Future research can use this model for evaluation of other industries.

\section{REFERENCES}

[1] R. S. Kaplan and D. P. Norton, "The Balanced Scorecard: Measures the Drive Performance, In Harvard Business School,” Harvard Business Review on Measuring Corporate Performance, Boston, MA: Harvard Business School Press, 1992.

[2] T. L. Saaty, “The Analytic Hierarchy Process,” NY: New York,” McGraw-Hill, 1980.

[3] K. P. Yoon and C. L. Hwang, "Multiple attribute decision making: An introduction,” Sage publication, 1995. 